\title{
Chemical-by-chemical bans leave people at risk
}

Previously published at www.cmaj.ca

A sk any person on the street what image comes to mind in response to the word "pollution" and it's liable to be a belching smokestack or an idling car. Few would say a familiar overstuffed sofa or a friendly toy such as a rubber duck. Yet increasingly the most worrisome and damaging pollutants affecting the health of Canadians are not the odoriferous industrial-grade variety that visibly waft from Canada's dwindling manufacturing centres (though these remain important), they are the invisible toxic ingredients of umpteen consumer products that litter our homes and offices. Some of these have achieved recent notoriety. For example, bisphenol A (BPA) - a known endocrine disruptor - is a component of polycarbonate plastic in baby bottles and in the resin linings of virtually every tin can in every Canadian kitchen cupboard.

My coauthor Bruce Lourie and I set out to draw back the curtain on this strange world of toxic chemicals in unlikely places in our new book Slow Death by Rubber Duck. To illustrate the ease with which these pollutants accumulate in the human body we experimented on ourselves, attempting to raise and lower levels of seven toxic chemicals (BPA, phthalates, brominated flame retardants, perfluorinated "non-stick" chemicals, triclosan, pesticides and mercury) in our blood and urine through the performance of common activities. Though our sample size of two is admittedly modest, the results were unprecedented and astonishing (since the book's publication the BPA results have been replicated with a much larger study). ${ }^{1}$ It turns out that the choices we make as consumers have a profound, and very rapid, effect on the pollution levels in our bodies. Through doing things that people do every day (e.g., cooking in polycarbonate plastic), Rick increased his urine levels of monoethyl phthalate (an ingredient in shampoos and hand creams) by 22 times, his levels of BPA by 7.5 times,

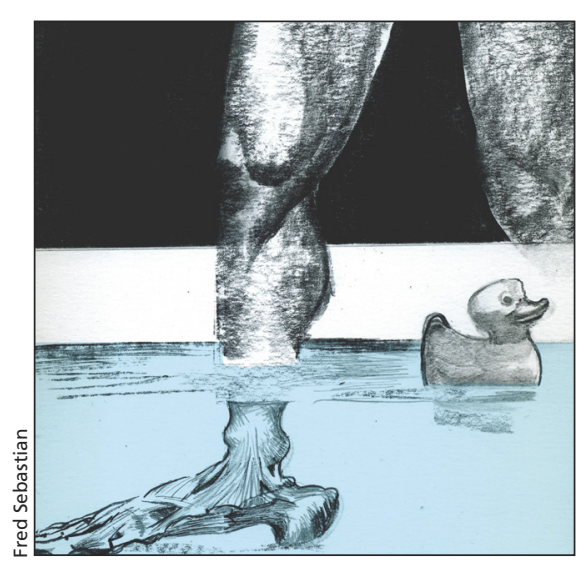

and his levels of triclosan (a common antibacterial agent) by a mind-blowing 2900 times. Bruce increased his mercury levels by 2.5 times. All of these chemicals have been identified as contributing to serious human health problems.

The good news is that governments are finally taking action to protect the environment and human health by restricting or banning many of these toxic chemicals. In April 2008, Canada became the first jurisdiction in the world to ban BPA from baby bottles. Similarly positive recent action has been taken in this country on phthalates in children's toys, deca BDE in consumer electronics and siloxanes (a silicone-based substance found in hair-care products). Even the most unlikely governmental champions are getting into the act. In 2008, a strong national ban on phthalates in toys was unanimously adopted - over vehement industry objection by the US Senate and signed into law by that well-known advocate of the precautionary principle: George W. Bush.

All this is very welcome, but given that there are tens of thousands of chemicals in commerce - many of which were placed on the market before the advent of proper safety testing can we really clean up our mess by duking it out one chemical at a time? Certainly not. The time has come to ask some more profound and sweeping questions about chemical regulation. With many less-toxic chemical formula- tions available, why are we even getting boxed into the ludicrous discussion of how to risk manage the continued use of these toxic ingredients in consumer products? One exciting new approach is to simply get rid of entire applications of chemical families if the uses are frivolous and potentially damaging: the recent Ontario and Quebec (and soon, we hope, New Brunswick) laws to ban the cosmetic use of pesticides are examples of this (and passed, in part, through the support of organizations representing doctors and nurses). The Kid-Safe Chemical Act is gaining steam in the US Congress and advances the commonsense proposition that if a synthetic chemical is detectable in infant cord blood (and there are hundreds of them) they should be phased out of production unless industry can conclusively demonstrate their safety.

The scientific evidence is clear: the toxic chemicals that form the basis of our modern lifestyle are the root cause of a considerable amount of human disease. Eliminating this threat is a challenge just as important, and requires as much ambition, as that which is necessary to combat climate change.

\section{Rick Smith PhD \\ Executive Director \\ Environmental Defence \\ Toronto, Ont.}

\section{REFERENCE}

1. JL Carwile, HT Luu, LS Bassett, et al. Use of polycarbonate bottles and urinary bisphenol A concentrations. Environ Health Perspec 2009;9:1368-72. Available: www.ehponline.org/members/2009 /0900604/0900604.pdf (accessed 2009 Aug. 25).

Rick Smith is Executive Director of Environmental Defence and coauthor, with Bruce Lourie, of Slow Death by Rubber Duck (Knopf Canada; 2009).

Have you got an opinion about this article? Post your views at www.cmaj.ca. Potential Salon contributors are welcome to send a query to salon@cmaj.ca 